\title{
EFFECTS OF USING ENGLISH PODCASTS ON IDIOMS AND VOCABULARY LEARNING OF IRANIAN EFL LEARNERS
}

\author{
Golyas Akhavan Tabatabaee \\ English Department, Isfahan (Khoarsgan) Branch, Islamic Azad University, Iran \\ E-mail: golyas90@gmail.com \\ Ehsan Rezvani \\ English Department, Isfahan (Khoarsgan) Branch, Islamic Azad University, Iran \\ E-mail: rezvani_ehsan_1982@yahoo.com
}

\begin{abstract}
APA Citation: Tabatabaee, G. A., \& Rezvani, E. (2019). Effects of using English podcasts on idioms and vocabulary learning of Iranian EFL learners. Indonesian Journal of Learning and Instruction, 2(1), 15-26. doi: 10.25134/ijli.v2i01.1680.
\end{abstract}

Received: 26-12-2018

Accepted: $14-02-2019$

Published: 01-04-2019

\begin{abstract}
This study is an attempt to explore the potential effects of using podcasts on idiom and vocabulary learning of Iranian EFL upper and lower intermediate learners as well as their attitudes toward learning via podcasts. To achieve the goals of the study, 100 participants who are made homogeneous in terms of language proficiency using an Oxford Placement Test (OPT) are selected, and are subsequently divided into four groups: two experimental groups and two control groups. Those students whose scores fall two standard deviations above the mean are considered as the upper intermediate group and those whose scores fall two standard deviations below the mean constituted the lower intermediate group. Then, researcher make vocabulary and idiom pre-tests are administered to assess the learners' knowledge of the target vocabulary and idioms prior to treatment. As for the treatment, the students in the control group are taught conventionally using the readings in an ELT textbook, whereas the experimental groups' learners are taught using podcasts containing idioms and vocabulary in focus. Finally, the learners are given a post-test parallel in form to the pre-test. The findings indicate that the learners who are taught via podcasts outperformed the control group on the post-test. Moreover, the findings show that learners have a significantly positive attitude toward learning via podcasts. The results will have implications for EFL teachers and materials developers.
\end{abstract}

Keywords: atittude; idiom; podcast; proficiency level; vocabulary.

\section{INTRODUCTION}

Idioms and metaphoric expressions are important parts of learning and understanding the second or foreign language. Gibbs (1992) suggests that students can further understand texts that contain metaphorical and lexical meanings if the understanding of figurative language is developed. As proposed by Honeck (1997), a language which is literally has the same meaning but is interpreted as something different is called figurative language. Idioms are also known as an important thing in a language consists of our vocabulary (Qualls, O'Brien, Blood, \& Hammer, 2003).

Learning is a cognitive process that involves conscious and active behavior. Students look for similarities and differences between new information and prior knowledge, and in this way they are able to effectively assimilate new learning into existing cognitive structures (Piaget, 1980). Language, according to Hudson (1980), one of the greatest achievements of mankind is the ability to learn language and it is the center of human life. Language consists of many different aspects that is important in 
learning. In English, learning and understanding idioms, metaphoric, and idiomatic expression are an important role. New technologies are affecting different aspects of life. Education, in particular, is a field that has undergone major changes in recent years. The development of digital communication methods, information transfer, and storage has had a significant influence on education, and technology development has made it possible for individuals with less computer skills to produce and disseminate information. As a result, teaching and learning now can occur almost at any time and in any place that has communication services. In addition, new technologies allow students ready access to a wide range of information and educational resources, as well as frequent contact with peers and mentors. Many teachers believe that different teaching methods play important roles in the quality of learning, especially learning a second or foreign language.

Caused by the entry of extraordinary technology has changed the tradition of teaching English dramatically. The increasing of language teaching becomes more productive and interesting by using technology. Besides that, one of the most significant aspects of social and language change is technology. Graddol (1997) assumes that education work and culture are affected by technology that is in the globalization process. The use of English has increased rapidly after 1960. Currently, in curriculum and language of imparting education, the role and status of English is the language of social context, political, sociocultural, business, education, industries, media, library, communication across borders, and key subject. It is also a crucial determinant for university entrance and processing well-paid jobs in the commercial sector.

In promoting student activities, initiatives of student and teaching effect in English class, multimedia technology has been shown to play a positive role. Nowadays, the way of our communication are changed by technological innovations which have gone hand in hand with the growth of English. As we know, the growth of the Internet has facilitated the growth of English and nowadays computers have been widely used by everyone. Because of this, there has been a very significant proliferation of literature concerning the use of technology in teaching English.

Podcasting is one of the powerful, emergent technological media that has been used in education for many years. Language learning has been recognized as one of the fields about to get help from the rapid development in podcasting. Research studies on podcasting have already acknowledged its potentiality and have documented much evidence that podcasts can greatly help develop learners' language skills, especially in developing learners' speaking and listening skills (Ashton-Hay \& Brookes, 2011; O'Bryan \& Hegelheimer, 2007)

A series of digital audio and video recordings uploaded on the web with the help of Rapid Simple Syndication (RSS) feeds are called podcasts (Lafferty \& Walch, 2006). On the internet, there are many types of podcasts such as television podcasts, radio podcasts, class podcasts, and individual or group podcasts.

Few articles have considered the theoretical aspects of podcasting (O'Bryan \& Hegelheimer, 2007; Rosell-Aguilar, 2007), while much of the literature surrounding podcasting and language learning has focused on the technical aspects and practical examples of podcasting projects (e.g., McCarty, 2005; Stanley, 2006, and Young, 2007), Blake (2008) suggested that the technology is theoretically and methodologically neutral. But the responses to what the practitioners understand or believe to be true about SLA are how technology is used its particular culture of practice is not neutral.

In Second Language Acquisition (SLA) research, podcasting has several theoretical foundations, esspecially in the areas of input, output, and motivation. Dervin (2006) argued that podcasts can help to reinforce 
autonomous learning and motivation. Motivation may be increased, speculated, due to the fact that students are creating authentic content for a real audience and not just for a grade, Stanley (2006). Moreover, Dervin (2006), if the underlined "students can", it means they can take the initiative to ask questions, interact and communicate with podcasters, thus providing opportunities for autonomy and motivation. Output is identified as important thing for second language learning.

A good number of language-specific articles have addressed podcasting and have provided practical ideas for its use in the classroom, (Fox, 2008; Schmidt, 2008; Young, 2007). Fox (2008) proposed that podcasts can also be set up like talk show and allow students to listen, create, and publish podcasts by using a talk radio podcast. There is a special podcast discussed by Fox, suggested a corresponding blog where information, or "show notes," about corresponding episodes were archived, and where listeners could communicate with the podcasters.

The importance of vocabulary in language learning has been undervalued in the past 50 years of ELT history, (Seal, 1991; Zimmerman, 1997). The role of vocabulary is typically considered in terms of the classic ELT methodologies and the theories of reading models. The important factors in reading and listening comprehension, speaking and writing fluency are influenced by knowledge of word meanings and the ability to access knowledge efficiently. In othe words, students can easily understand the language when supported by their language comprehension. Like Widdowson (1989), McKeown (2002) state that the heart of language understanding and use is knowledge of vocabulary.

The need and opportunity to investigate the effects of multimedia on vocabulary acquisition has created by computer-assisted language learning (CALL) in recent years. Thus far, numerous studies (Al-Seghayer, 2001; Groot, 2000; Hulstijn, 2000; Laufer \& Hill, 2000; Siribodhi, 1995) have shown that computerized media and a multimedia environment can be helpful for learning foreign language vocabulary.

Gainer and Lapp (2010) state that students' knowledge and interests outside of school are recognized, respected, and used as part of instructional images in class culture if engaged learning is involved. Martinez-Lage (1997), Al-Seghayer (2001), Wood (2001), reported that the potentiality of computer was the multimodal presentations of any kind of instructions. Since the multimedia presentations provide immediate access to the available annotated information in a program, including textual, audio, and visual annotations, these pieces of information attached to a word enables readers to "confirm or reject hypotheses made about the meaning of a word" as Martinez-Lage (1997) contends. In this respect, Mayer (2005) suggest that helping students build referential connections between two forms of mental representation systems namely verbal and visual is a function of multimedia programs. When verbal and visual materials are presented simultaneously, referential connections will be easier to build.

Ghabanchi and Anbarestani (2008) in their study explored the effect of CALL on vocabulary learning. They indicated that students can have an intensive mental process and have a strong memory of words by using CALL program. CALL also produces better results in contextualized vocabulary learning than ordinary desktop dictionary method. Xin and Rieth (2001), and also assert that computer technology increases the probability of idiom recall from one's long term memory. Al-Seghayer (2001) suggests that information will be more meaningful and more memorable if it is influenced by visuals' contextual richness and cultural authenticity. Using multimedia technology to simultaneously present the audio, visual and textual information to the learners, the new idioms can be presented in a contextual setting which, according to studies such as Ghabanchi \&Anbarestani (2008), leads to higher immediate and delayed post-test scores in comparison with 
learners who have access to merely textual information.

\section{METHOD}

To achieve the goals of this study, 120 students at Pooyesh Language Center in Esfahan were randomly selected. Then, an Oxford Placement Test (OPT), (vocabulary and grammar sections), was run to select 100 homogeneous students based on the normal distribution of the scores using the OPT level chart. All the participants were within the age range of 15 to 25 years and they were all native speakers of Persian. After choosing 100 homogeneous participants out of 120 , they were randomly assigned to two experimental groups and two control groups (25 students each). Those students whose scores fell 2 standard deviations above the mean constituted the upper intermediate group and those whose scores fell 2 standard deviations below the mean made the lower intermediate group.

In this study, four types of instruments were employed for data collection. There were Oxford Placement Test, pre-test, posttest, and questionnaire. An Oxford Placement Test (OPT), (grammar and vocabulary sections), was conducted whose validity and reliability had already been confirmed. It consisted of 70 multiple-choice items including 20 listening items, 20 reading items, and 30 items related to language use. Beside that, a researcher made multiple choice pre-test consisting of 20 vocabulary test items and 20 idiom test items was run to measure the knowledge of vocabulary and idioms prior to treatment, whose validity and reliability were checked. A researcher-made post-test which was parallel to the pre-test was used to measure vocabulary and idiom knowledge after the treatment. Moreover, a researcher made questionnaire of 24 test items was designed to discover the attitudes of the learners toward using podcast. As for the reliability of the questionnaire, alpha Cronbach method was applied. With regards to validity of the tests and questionnaire, two expert judges in the field of TEFL observed the tests and determined their validity.
This study was conducted in Pooyesh Language Center. As it was mentioned earlier, the population of the study was 120 students. Then, an Oxford Placement Test (OPT), (vocabulary and grammar sections), was run to select 100 homogeneous students based on the normal distribution of the scores using the OPT level chart. Next, they were randomly divided into four equal groups: two experimental and two control groups at upper and lower intermediate levels.

Prior to the treatment, the pretest including 20 idiom test items and 20 vocabulary test items was administered to the groups of the study to discover the participants' level of knowledge of English idioms and vocabulary. As for the treatment, every session, some new idioms and vocabulary items were taught about 30 minutes to students in the experimental groups through podcasts. The students in the control group were taught using the readings in Select Readings by Linda Lee \& Eric Guandersen, (1995), whereas the experimental groups' learners were taught using podcasts only.

The participants in experimental groups listened to podcasts containing idioms and vocabularies in class twice a week. The teacher provided them with necessary feedback either explicitly or implicitly. They also were asked to write one sentence to exchange with their partners and bring their assignments to the class for the next session. After the experiment was done, the post test was given to the groups in order to find the gains in idiom and vocabulary learning. Finally, the researcher gave a questionnaire to the learners to obtain their attitudes toward learning by podcasts.

\section{RESULTS AND DISCUSSION \\ Results for upper-intermediate learners}

One of the objectives of the current study was to investigate whether listening to podcasts played a significant role in upper intermediate Iranian EFL learners' acquisition of vocabulary and idiom or not. To achieve this end, UIEG and UECG learners' pre-test scores were first compared 
using an independent-samples $t$ test to make certain they were not drastically different in terms of knowledge of idiom and vocabulary; their post-test scores were compared via the same statistical procedure as well. Table 1 displays the descriptive statistics for these analyses.

Table 1. Descriptive statistics for comparing pre-test scores of UIEG and UICG and their

\begin{tabular}{lcccc}
\multicolumn{5}{c}{ post-test scores } \\
& $\boldsymbol{N}$ & Mean & $\begin{array}{c}\text { Std. } \\
\text { Deviation }\end{array}$ & Std. Error Mean \\
\hline UIEG Pre-test & 25 & 11.94 & 2.37 & .57 \\
UICG Pre-test & 25 & 11.74 & 2.41 & .52 \\
& & & & \\
UIEG Post-test & 25 & 19.11 & 1.62 & .21 \\
UICG Post-test & 25 & 13.46 & 2.53 & .47 \\
& & & & \\
\hline
\end{tabular}

As it can be seen in table 1, the difference between the pre-test scores of the UIEG $(M=11.94)$ and the UICG $(M=$ 11.74) was minimal, but the post-test scores of the UIEG $(M=19.11)$ and the UICG $(M=$
13.46) were considerably different. To find out whether the differences in the pre-test and post-test scores of the two groups were statistically significant or not, the following $t$ test table had to be consulted.

Table 2. Results of the Independent-Samples t-Test comparing pretest scores of UIEG and UICG and their post-test scores

\begin{tabular}{|c|c|c|c|c|c|c|c|c|c|}
\hline & \multicolumn{3}{|c|}{$\begin{array}{c}\text { Levene's Test for } \\
\text { Equality of } \\
\text { Variances } \\
\end{array}$} & \multicolumn{4}{|c|}{$t$ test for Equality of Means } & & \\
\hline & \multirow[t]{2}{*}{$F$. } & \multirow[t]{2}{*}{ Sig. } & \multirow[t]{2}{*}{$t$} & \multirow[t]{2}{*}{$d f$} & \multirow{2}{*}{$\begin{array}{l}\text { Sig. } \\
(2- \\
\text { tailed })\end{array}$} & \multirow{2}{*}{$\begin{array}{c}\text { Mean } \\
\text { Differenc } \\
\text { e }\end{array}$} & \multirow[t]{2}{*}{$\begin{array}{l}\text { Std. Error } \\
\text { Difference }\end{array}$} & \multicolumn{2}{|c|}{$\begin{array}{c}\text { 95\% Confidence } \\
\text { Interval of the } \\
\text { Difference }\end{array}$} \\
\hline & & & & & & & & Lower & Upper \\
\hline Pre-test & .22 & .63 & .22 & 48 & .79 & .20 & .75 & -1.54 & 1.91 \\
\hline Post-test & 66.00 & .000 & 1.87 & 48 & .000 & 5.65 & .69 & 6.22 & 9.05 \\
\hline
\end{tabular}

As it could be seen in table 2, there was not a statistically significant difference in pre-test scores for UIEG and UICG, $t(48)=$ $.22, p=.79$ (two-tailed). This indicated that the two groups were not significantly different at the outset of the study with regard to their knowledge of vocabulary and idiom. The difference between UIEG and UICG learners' post-test scores, however, was statistically significant since the $p$ value under the Sig, (2-tailed) column was less than the significance level (i.e. .000<.05). This means that the treatment had been effective as far as the vocabulary/idiom knowledge of upper intermediate Iranian EFL learners was concerned giving rise to the claim that listening to podcasts significantly improved the vocabulary and idiom knowledge of the learners at the upper intermediate level of proficiency.

\section{Results for lower-intermediate learners}

Another objective of the present study was to see whether listening to podcasts could significantly improve lower intermediate EFL learners' knowledge of idiom and vocabulary or not. In order to find an answer to this question, LIEG and LICG learners' 
Golyas Akhavan Tabatabaee \& Ehsan Rezvani

Effects of using English podcasts on idioms and vocabulary learning of Iranian EFL learners

pre-test scores were compared using an the descriptive statistics for the pre-test and independent-samples $t$ test; likewise, their post-test scores of the LIEG and LICG post-test scores were compared via another learners. independent-samples $t$ test. Table 3 shows

Table 3. Descriptive statistics for comparing pretest scores of LIEG and LICG learners and their post-test scores

\begin{tabular}{lcccc}
\hline & $\boldsymbol{N}$ & Mean & $\begin{array}{c}\text { Std. } \\
\text { Deviation }\end{array}$ & Std. Error Mean \\
\hline LIEG Pre-test & 25 & 10.53 & 1.69 & .43 \\
LICG Pre-test & 25 & 10.34 & 2.75 & .57 \\
& & & & .45 \\
LIEG Post-test & 25 & 15.08 & 1.65 & .51 \\
LICG Post-test & 25 & 13.26 & 2.90 & \\
\hline
\end{tabular}

Table 3 illustrates that the difference between the pretest scores of the LIEG $(M=$ 10.53) and the LICG $(M=10.34)$ was not substantial, but the difference between the post-test scores of the LIEG $(M=15.08)$ and the LICG $(M=13.26)$ was comparatively larger. To figure out whether the differences in the pre-test and post-test scores of the two groups were statistically significant or not, the following $t$ test table (and the $p$ value therein) had to be checked.

Table 4. Results of the Independent-Samples t-Test comparing pretest scores of LIEG and LICG and their post-test scores

\begin{tabular}{|c|c|c|c|c|c|c|c|c|c|}
\hline & $\begin{array}{r}\text { Leve } \\
\text { for } \mathbf{E} \\
\mathrm{Va}\end{array}$ & $\begin{array}{l}\text { Test } \\
\text { ity of } \\
\text { ces }\end{array}$ & & & & for Equali & of Means & & \\
\hline & $F$. & Sig. & $t$ & $d f$ & $\begin{array}{l}\text { Sig. } \\
(2-\end{array}$ & $\begin{array}{c}\text { Mean } \\
\text { Differenc }\end{array}$ & $\begin{array}{l}\text { Std. Error } \\
\text { Difference }\end{array}$ & $\begin{array}{r}95 \% \mathrm{C} \\
\text { Interv } \\
\text { Diff }\end{array}$ & $\begin{array}{l}\text { fidence } \\
\text { of the } \\
\text { ence }\end{array}$ \\
\hline & & & & & & & & Lower & Upper \\
\hline Pre-test & 2.31 & .11 & .09 & 48 & .89 & .19 & .71 & -1.33 & 1.43 \\
\hline Post-test & 1.55 & .23 & .73 & 48 & .04 & 1.82 & .66 & -1.22 & 1.35 \\
\hline
\end{tabular}

Table 4 depicts there was not a statistically significant difference in pretest scores for LIEG and LICG learners, $t(48)=$ $.09, p=.98$ (two-tailed). This meant that the two groups did not differ significantly in terms of their idiom and vocabulary knowledge prior to the implementation of the treatment. However, the difference between LIEG and LICG learners' post-test scores reached statistical significance since the $p$ value under the Sig, (2-tailed) column was less than the significance level (i.e. .04 < $.05)$. This implies that the treatment had a significant positive effect on the vocabulary/idiom knowledge of lower intermediate Iranian EFL learners.

\section{Comparing lower- and upper-intermediate learners}

In order to compare the achievements of the lower- and upper-intermediate learners in the experimental groups, one could cast a look at the mean differences for the post-test comparisons made in the previous sections. In Table 2, the mean difference for the posttest scores of the upper intermediate learners 
was 5.65. This means the upper intermediate experimental group outperformed the upper intermediate control group by a mean difference of 5.65 on the post-test. On the other hand, the mean difference for the posttest comparison of the lower intermediate learners (as shown in Table 4.) was 1.82. This means that the lower intermediate experimental group had a better performance than the lower intermediate control group on the post-test by 1.82 mean difference. The overall conclusion from this part could be that the treatment (i.e. listening to podcasts) was more effective for the improvement of upper intermediate learners than it was the improvement of lower intermediate learners.

An alternative approach to comparing the achievements of lower- and upperintermediate learners would be through comparing the effect sizes of the difference, which could be calculated through the eta squared formula (eta squared $=\mathrm{t}^{2} / \mathrm{t}^{2}+d f$ ) The calculated effect size for upper intermediate learners was .067, while the obtained value for lower intermediate learners was .010. According to Cohen (1988, pp. 284-287, as cited in Pallant, 2011), the effect size is small if the eta squared value is falls between .01 and .06, moderate if it is between .06 and .14, and large if it is greater than .14. In this case, the effect size for lower intermediate learners was small, but for upper intermediate learners was moderate. So the conclusion made above was verified through this alternative approach.

\section{Results for the attitude questionnaire}

As it was previously stated, the third research question of the study intended to examine whether EG learners' attitude towards using podcasts for language learning in general and vocabulary/idiom learning in particular was positive or not. The results for UIEG and LIEG learners are presented below.

\section{UIEG learners' attitudes towards using podcasts}

To unravel the attitudes of the UIEG learners towards the treatment, one-sample $t$ test was employed. This statistical technique compares the mean score of a distribution against a constant (which was 3.00 in this analysis since the choices in the Likert-scale questionnaire ranged from 1 to 5 and the average value of the choices was 3.00). Table 5 shows the results of descriptive statistics performed for this purpose.

Table 5. Descriptive statistics for UIEG learners' attitude scores

\begin{tabular}{ccccc}
\hline & $N$ & Mean & Std. Deviation & $\begin{array}{c}\text { Std. Error } \\
\text { Mean }\end{array}$ \\
\hline UIEG Questionnaire & 25 & 4.63 & .21 & .14 \\
\hline
\end{tabular}

For the UIEG, the attitude mean score was found to be 4.63, which was larger than 3.00. This means that the learners' attitudes toward using podcasts were positive. Whether this positive attitude was of statistical significance or not could only be determined by taking a look at the Sig. (2-tailed) value in the $t$ test table below (Table 6).

Table 6. One-Sample t-Test results for UIEG learners' attitude scores

\begin{tabular}{|c|c|c|c|c|c|c|}
\hline & \multicolumn{6}{|c|}{ Test Value $=\mathbf{3}$} \\
\hline & \multirow[t]{2}{*}{$t$} & \multirow[t]{2}{*}{$d f$} & \multirow[t]{2}{*}{$\begin{array}{c}\text { Sig. } \\
\text { (2-tailed) }\end{array}$} & \multirow{2}{*}{$\begin{array}{c}\text { Mean } \\
\text { Difference }\end{array}$} & \multicolumn{2}{|c|}{$\begin{array}{l}\text { 95\% Confidence } \\
\text { Interval of the } \\
\text { Difference }\end{array}$} \\
\hline & & & & & Lower & Upper \\
\hline UIEG Questionnaire & 31.43 & 24 & .000 & 1.63 & 1.65 & 1.87 \\
\hline
\end{tabular}


(i.e. 3.00) since the $p$ value was smaller than the specified level of significance $(.000<$ $.05)$. It could be thus concluded that the relevant treatment (i.e., the use of podcasts) was significantly welcome by the UIEG learners.

\section{LIEG Learners' Attitudes Towards Using Podcasts}

Another one-sample $t$ test was utilized to find out if LIEG learners' attitude towards using podcasts for learning idiom/vocabulary was positive or not. Table 7 displays the results of descriptive statistics performed for this analysis.

Table 7. Descriptive statistics for LIEG learners' attitude scores

\begin{tabular}{ccccc}
\hline & $N$ & Mean & Std. Deviation & $\begin{array}{c}\text { Std. Error } \\
\text { Mean }\end{array}$ \\
\hline LIEG Questionnaire & 25 & 4.33 & .31 & .11 \\
\hline
\end{tabular}

As for the LIEG learners, the attitude mean score appeared to be 4.33 , which was greater than 3.00. This indicates that the LIEG learners' attitudes toward using podcasts for idiom/vocabulary learning was

positive. However, whether this positive attitude was statistically significant or not could only be found out by examining the Sig. (2-tailed) value in the $t$ test table below (Table 8).

Table 8. One-Sample t-Test results for LIEG learners' attitude scores

\begin{tabular}{ccccccc}
\hline & \multicolumn{9}{c}{ Test Value $=3$} \\
\cline { 2 - 6 } & $t$ & $d f$ & $\begin{array}{c}\text { Sig. } \\
\text { (2-tailed) }\end{array}$ & $\begin{array}{c}\text { Mean } \\
\text { Difference }\end{array}$ & $\begin{array}{c}\text { 95\% Confidence } \\
\text { Interval of the } \\
\text { Difference }\end{array}$ \\
\hline EG2 Questionnaire & 16.21 & 24 & .000 & 1.33 & Lower & Upper \\
\hline
\end{tabular}

Based on the information in table 8, there was a statistically significant difference between the LIEG learners' mean attitude score $(M=4.33)$ and the average value of the choices (i.e. 3.00) because of the fact that the $p$ value was smaller than the specified level of significance $(.000<.05)$. It could thus be inferred that the treatment was viewed to be significantly positive by the learners in LIEG.

\section{Discussion for research question 1}

Considering the first research question for the upper intermediate learners, the results of the present study indicated that the two groups were roughly similar at the beginning of the experiment, but the UIEG, due to being exposed to the treatment, managed to significantly outperform the UICG on the posttest, giving rise to the claim that listening to podcasts significantly improved the vocabulary and idiom knowledge of the learners at the upper intermediate level of proficiency.

Based on the same research question for the lower intermediate learners, the results of the current study show that the two groups were not very much different at the beginning of the experiment. Nonetheless, the LIEG significantly outperformed the LICG on the posttest, giving rise to the conclusion that listening to podcasts significantly improved lower intermediate learners' vocabulary and idiom knowledge. The practice of podcasting technology has been used to develop vocabulary and idiom learning and improving memorization by a good number of researchers. In a study by Allan (2007), students extensively used the provided materials on their personal computers. The results of this study demonstrated that without proper guidance and encouragements of teachers, students remain to be lethargic towards using 
podcasting that is similar to the findings of the present study.

The findings of this study also support the study conducted by Facer et al. (2009), who found that incorporating podcasting technology into classroom teaching will result in improvement in all language skills as well as comprehension of vocabulary. Likewise, a study by Lin, and Chen (2012) revealed that by sending podcasting materials to students' devices including their smartphones, listening abilities and the level of vocabulary knowledge have improved considerably.

However, in a different experiment from the present study, Palalas (2009) revealed that implementing podcasting skill will result in rote memorization of vocabulary. In this work, despite positive feedbacks from students, little amount of peer connection was observed between participants. Stockwell (2010) assumes that podcasting can be regarded as a valuable resource for providing audiovisual material but does not have important elements of language learning, such as interaction which is not in line with the findings of this study. In the present study, podcasts are considered as the main teaching tool which is opposed to a study conducted by Abdous et al., (2012) who concluded that supplementary podcasts can have stronger effects on language learning than podcasts as the main teaching tools. By supplementary, they mean podcasts are not considered to be the main teaching and learning tools but something which can help in the process of teaching in addition to other tools.

\section{Discussion for research question 2}

In order to compare the achievements of the lower- and upper-intermediate learners in the experimental groups, one could cast a look at the mean differences for the posttest comparisons. Considering the second research question, the results of the present study showed that the treatment (i.e. listening to podcasts) was more effective for the improvement of upper intermediate learners than it was for the improvement of lower intermediate learners.

Rosell-Aguilar (2007) suggested that the findings of this study can be supported by appropriate materials which can be found in the wealth of podcasts resources which was available on the website. According to the definition of extensive listening, students should be "doing a lot of easy, comprehensible, and enjoyable listening practice" (Chang \& Millet, 2013). As proposed by Putman and Kingsey (2012) and Yeh (2013) highlighted, students were much more likely to continue listening to podcasts because the materials were interesting and easy to find based on their level of proficiency. The same is supported in the present study.

\section{Discussion for research question 3}

The results of this study indicated that the relevant treatment (i.e., the use of podcasts) was significantly welcome by the UIEG and LIEG learners. Language learning is influenced by many factors and the most significant and facilitating factor is positive attitude (Mian, 1998). It is sometimes difficult to motivate students outside the classroom, but the use of podcasts can assist this issue.

Podcasts have the potentiality to create both intrinsic and extrinsic motivation among students (O-Bryan \& Hegelheimer 2007). Kavaliauskienè and Anusienè (2009) used survey questions to examine learners' perceptions of online listening to podcasts. The participants of this study were taken from Mykolas Romeris University, Lithuania. In line with the findings of the present study, most of the participants showed positive attitudes to the techniques of developing listening skills using podcasts.

Kim and King (2011) claimed that students' attitudes toward podcasts varied depending on their previous experiences with various types of computer technologies. The use of podcasts also reduces students' anxiety and creates a sense of belonging to a learning community, (Chan \& Lee, 2005). Our findings lend further support to the 
findings of Heilesen (2010) who claimed that students generally show very good attitudes towards podcasting and "reports of rejection of podcasting are rare" (p.3). Although the studies above confirm the positive attitudes toward using podcasts, some others, contrary to our findings, have revealed no effect on students learning or attitude after using podcasts (Weatherly, Grabe \& Arthur, 2002; Daniel \& Woody, 2010). Fernandez, et al. (2009) in another study made judgments about the feelings, understanding, and the reactions of some participants who used podcasts during one semester. According to their findings, they stated that podcasting was not a substitute for traditional learning system in the participants' opinions; it just increased the participants' motivation.

The use of podcasts to disseminate instructional materials online has elicited considerable interest among colleges and universities (Dupugne, et al., 2009). An example is Lee \& Chan's (2007) study in which distance learners, who were studying an information technology subject, were given some podcasts for performing additional listening activities. At the end of the semester the results of the survey revealed that the learners had very positive feelings about their experience which is in line with the findings of the present study.

\section{CONCLUSION}

The findings of the present study demonstrate that both UIEG and LIEG groups performed better in vocabulary and idiom learning after receiving the treatment. Second, the treatment (i.e. listening to podcasts) was more effective for the improvement of upper intermediate learners than it was the improvement of lower intermediate learners, and third that the relevant treatment (i.e., the use of podcasts) was significantly welcome by the UIEG and LIEG learners. Thus, the findings of the present study support employing new and dynamic ways of teaching idiom and vocabulary. In fact, it can be realized that teaching aids have become more varied since computer technology has the capacity to transfer files and sounds everywhere, every time. As such, the use of technology is more likely to leave a deeper impression on learners' memory. The finding could also assist teachers to redefine their roles under multimedia context. They should no longer stick to the traditional way of teaching idiom and vocabulary, in which they try to explain every new word and idiom in great detail, often with examples found in dictionaries. Practical implications could be drawn up concerning of instructional aids, and teaching aspects of idiom and vocabulary.

Thus, according to the results of this study, the use of podcasts should be advocated in all educational fields. It can be useful for software developers to design a soft-ware in which learners can easily find the podcasts in order to achieve educational purposes. The finding of this study would also help syllabus designers to include podcasts along with some instructions in their textbooks.

\section{REFERENCES}

Abdous, M., Facer, B. R., \& Yen, C. (2012). Academic effectiveness of podcasting: A comparative study of integrated versus supplemental use of podcasting in second language classes. Computers and Education, 58, 43-52.

Allan, S. (2007). Podcasts and embedded audio to support language learning. Warwick Interactions Journal, 30(2), 1-12.

Al-Seghayer, K. (2001). The effect of multimedia annotation modes on L2 vocabulary acquisition: A comparative study. Language Learning \& Technology, 5, 202-232.

Ashton-Hay, S., \& Brookes, D. (2011). Here's a story: Using student podcasts to raise awareness of language learning strategies. EA Journal, 26(2), 15-27.

Blake, R. J. (2008). Brave new digital classroom: Technology and foreign language learning. Washington DC: Georgetown University Press.

Chang, C. S., \& Millett, S. (2013). The effect of extensive listening on developing L2 listening fluency: Some hard evidence. ELT Journal, 68(1), 31-40.

Daniel, D.B., \& Woody, W.D. (2010). They hear, but do not listen: Retention for podcasted material in a classroom context. Teaching of Psychology, 37. 199-203.

Dupugne, M., Millette, D.M., \& Grinfeder, K. (2009). Effectiveness of video podcast use as a revision 
Indonesian Journal of Learning and Instruction Volume 2, Issue 1, April 2019
p-ISSN 2614-8250, e-ISSN 2614-5677

https://journal.uniku.ac.id/index.php/IJLI tool. Journalism and Mass Communication Educator, 64, 570.

Fox, A. (2008). Using podcasts in the EFL classroom. TESL-EJ, 11(4).

Ghabanci, Z., \& Anbarestani, M. (2008). The effect of CALL program on expanding lexical knowledge of EFL Iranian intermediate learners. The Reading Matrix, 8(2), 40-56.

Gibbs, R.W. (1992). What do idioms really mean? Journal of Memory and language, 2(3), 34-55.

Honeck, R.P. (1997). A proverb in mind: The cognitive science of proverbial wit and wisdom. Mahva, NJ: Erlbaum.

Hudson, R. A. (1980). Sociolinguistics. Cambridge: Cambridge university press.

Hulstijn, J. H. (2000). The use of computer technology in experimental studies of second language acquisition: A survey of some techniques and some ongoing studies. Language Learning and Technology, 3(2), 32-43.

Kavaliauskienè, G., \& Anusienè, L. (2009). English for specific purposes: Podcasts for listening skills. Coactivity: Philology, Educology, 17(2), 28-37.

Kim, D., \& King, K. (2011). Implementing podcasts with ESOL teacher candidates' preparation: Interpretations and implication. International Forum of Teaching and Studies, 7(2), 5-19.

Lafferty, M., \& Walch, R. (2006). Tricks of the podcasting masters. New York: Que.

Laufer, B., \& Hill, M. (2000). What lexical information do L2 learners select in a CALL dictionary and how does it affect word retention? Language Learning and Technology, 3(2), 58-76.

Lin, Y-T., \& Chen, H-J. (2012). Investigating the effects of podcasts via smartphones on foreign language learning. In J. Colpaert, A. Aerts, W-C. V. Wu, \& Y-C. J. Chao (Eds.), The medium matters, Proceedings $15^{\text {th }}$ International CALL Conference. McCarty, S. (2005). Spoken Internet to go: Popularization through podcasting. JALT CALL, 1(2), 67-74.

Mayer, R. E. (Ed.). (2005). The Cambridge handbook of multimedia learning. London: Cambridge University Press.

McKeown, M. G., L. (2002). Bringing words to life: Robust vocabulary instruction. New York, NY: Guilford.

Mian, A.H. (1998). Motivation and attitudes of beginning and intermediate level Panjabi students Learning English as a second language. Unpublished doctoral Dissertation, Indiana University of Pennsylvania, Indiana. PA.

Palalas, A. (2011). ESP for busy college students: Is the blend of in-class, online \& mobile learning the answer? The IALLT Journal, 41(1), 108136.
Piaget, J. (1980). The psychogenesis of knowledge and its epistemological significance. In $\mathrm{M}$. Piattelli-Palmarini (Eds.), Language and learning: The debate between Jean Piaget and Noam Chomsky (pp.22-34). Cambridge, MA: Harvard University Press.

Putman, S. M., \& Kingsley, T. (2012). The Atoms Family: Using podcasts to Enhance the development of science vocabulary. The Reading Teacher, 63(2), 100-108.

Qualls, C. D., Treaster, B., Blood, G. W., \& Hammer, C. S. (2003). Lexicalization of idioms in urban fifth graders: A reaction time study. Journal of Communication Disorders, 36(4), 245-261.

Rosell-Aguilar, F. (2007). Top of the pods: In search of a podcasting 'pedagogy' for language learning. Computer Assisted Language Learning, 20, 471-492.

Schmidt, J. (2008). Podcasting as a learning tool: German language and culture every day. Unterrichtspraxis, 41, 186-194.

Seal, B. D. (1991). Vocabulary learning and teaching. In M. Celce-Murcia (Ed.), Teaching English as a second or foreign language (pp. 296-311). Boston, MA: Heinle \& Heinle.

Siribodhi, T. (1995). Effects of three interactive multimedia CALL programs on the vocabulary acquisition of elementary level EFL students (Doctoral dissertation, University of Kansas, 1995). Dissertation Abstract International, 56(09), 3552A.

Stanley, G. (2006). Podcasting: Audio on the internet comes of age. TESL-EJ 9(4), 1-7.

Stockwell, G. (2010). Using mobile phones for vocabulary activities: Examining the effect of the platform. Language Learning \& Technology, 14(2), 95-110.

Weatherly, J., M. Grabe, \& Arthur. (2002). Providing introductory psychology students access to lecture slides via Blackboard 5: A negative impact on performance. Journal of Educational Technology Systems, 31, 463- 74.

Wood, J. (2001). Can software support children's vocabulary development? LLT Journal, 5(1), 166-201.

Xin, J. F., \& Rieth, H. (2001). Video-assisted vocabulary instruction for elementary school students with learning disabilities. Information Technology in Childhood Education Annual, 87-103.

Yeh, C. (2013). An investigation of a podcast learning project for extensive listening. Language Education in Asia, 4(2), 135-149.

Young, D. J. (2007). iPods, MP3 players and podcasts for FL learning: Current Practices and future considerations. NECTFL Review, 60, 39-49.

Zimmerman, C. (1997). Do reading and interactive vocabulary instruction make a difference? An empirical study. TESOL Quarterly, 8(3), 223256. 
Golyas Akhavan Tabatabaee \& Ehsan Rezvani

Effects of using English podcasts on idioms and vocabulary learning of Iranian EFL learners 